\title{
Application of Integral Calculus in Kinematics
}

\author{
S. Sathyapriya ${ }^{1}$, P. Jeevanantham ${ }^{2}$, M. Mukesh ${ }^{3}$, R. Lokesh ${ }^{4}$, T. Selva Muhillan ${ }^{5}$ \\ ${ }^{1}$ Assistant Professor, Sri Krishna Arts and Science College, Coimbatore, Tamil Nadu, India \\ 2,3,4,5 UG Scholar, Department of Mathematics, Sri Krishna Arts and Science College, Coimbatore, Tamil Nadu, \\ India
}

\begin{abstract}
Kinematics is the study of the motion of mechanical points, bodies and systems without consideration of their associated physical properties and the forces acting on them. The study is often referred to as the geometry of motion, and it models these motions mathematically using algebra. The systems in kinematics are modeled to calculate such things as speeds and ratios. Kinematics is very useful in the conceptual design of mechanical systems. Initial geometries and velocities of bodies are a part of the model. While kinematics can help determine whether a design is theoretically possible, there are more complexities when designing something for the real world. Without consideration of materials, and the forces acting upon them, many theoretically possible designs would be prone to failure. Kinetics, in contrast to kinematics, does consider physical properties such as the mass of the bodies or the forces driving them. Kinetics is logically deduced from kinematics by way of algebraic calculation of physical properties and forces. Kinetics takes into account physical forces and properties including material properties, like mass rigidity, and tensile or compressive strength.
\end{abstract}

Keywords : Mechanical Points, Bodies, Mass Rigidity, Tensile, Compressive Strength

\section{INTRODUCTION}

\section{APPLICATION OF KINEMATICS IN REAL WORLD}

In many instances it is only important to know how an object moves, without consideration of the forces causing the motion.

$>$ In machine components, it is common to use kinematics analysis to determine the (unknown) speed of an object, that is connected to another object moving at a known speed

To determine the linear velocity of a piston connected to a flywheel that is turning at a known speed

$>$ Old type writing machine, Pendulum

$>$ Trainmoving, Moving water in a river

$>$ Flying airplane, Bowling and hitting in cricket, shooting in basketball
The motion of planets around sun

> Studying kinematics gives engineers insight of how the machine functions and what design aspect can be modified to achievea required motion
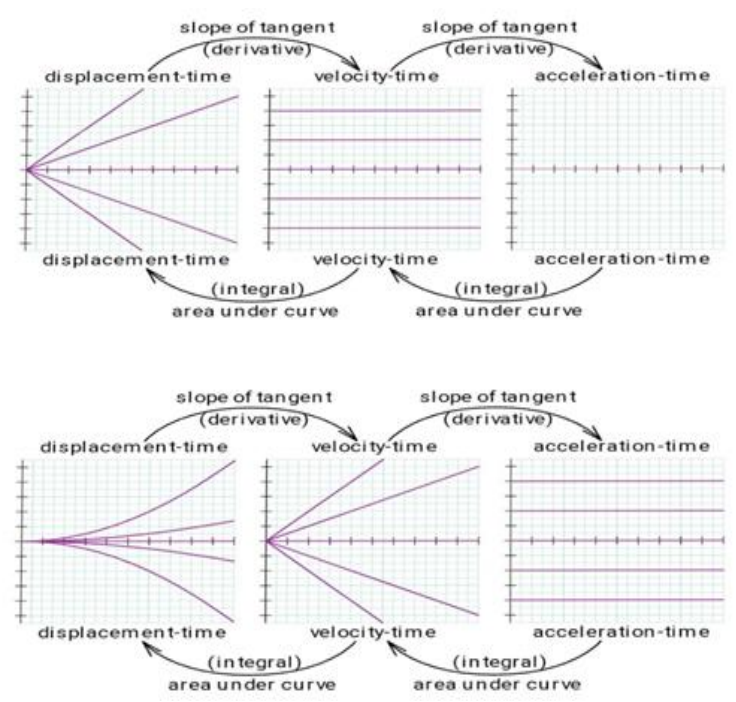


\section{METHODS AND MATERIAL}

\section{USE OF CALCULUS IN KINEMATICS}

\section{DERIVING THREE EQUATIONS OF MOTION}

- Acceleration is the rate of change of velocity of an object with respect to time. From acceleration,we derive first equation of motion

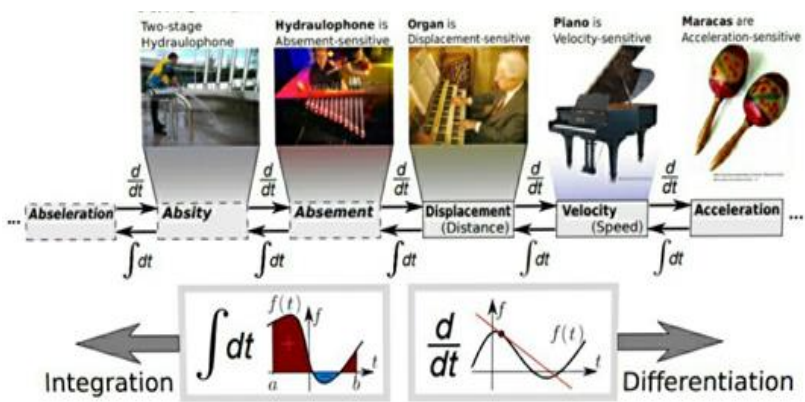

Fig. I. The study of integral kinematics originated with water flow . The hydraulophone (underwater pipe organ) exhibits the phenomenon of absement. The two-stage hydraulophone exhibits the phenomenon of absity (the doubleintegral of displacement).

\section{First Equation of Motion}

$$
\begin{gathered}
\mathrm{a}=\mathrm{dv} / \mathrm{dt} \\
\mathrm{dv}=\mathrm{adt} \\
\int_{v 0}^{v} d v=\int_{0}^{t} a \mathrm{dt} \\
\mathrm{v}-v_{0}=\mathrm{at} \\
\mathrm{v}=v_{0}+\mathrm{at}
\end{gathered}
$$

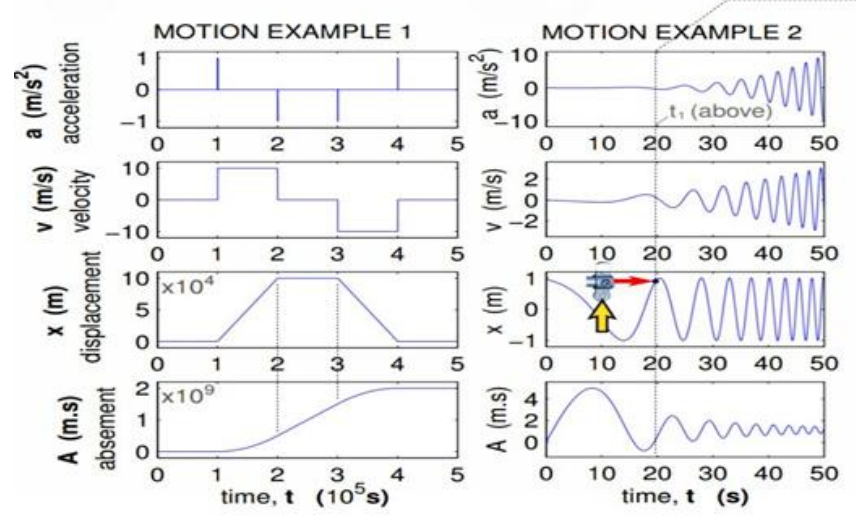

- Velocity is a vector expression of the displacement that an object or particle undergoes with respect to time. From velocity , we derive second equation of motion
Second Equation of Motion

$$
\begin{aligned}
& \mathrm{v}=\mathrm{ds} / \mathrm{dt} \\
& \mathrm{ds}=\mathrm{vdt} \\
& \mathrm{ds}=\left(v_{0}+\mathrm{at}\right) \mathrm{dt} \\
& \int_{s 0}^{s} d s=\int_{0}^{t}\left(v_{0}+\mathrm{at}\right) \mathrm{dt} \\
& \mathrm{s}-s_{0}=v_{0} \mathrm{t}+\mathrm{a} t^{2} / 2 \\
& \mathrm{~s}=s_{0}+v_{0} \mathrm{t}+\mathrm{a} t^{2} / 2
\end{aligned}
$$

- From first and second equations,we derive third equation of motion

\section{Third Equation of Motion}

$$
\begin{aligned}
& \mathrm{dv} / \mathrm{ds}=\mathrm{a}^{*} 1 / \mathrm{v} \\
& \mathrm{v} \mathrm{dv}=\mathrm{a} \mathrm{ds} \\
& \int_{v 0}^{v} v \mathrm{dv}=\int_{s 0}^{s} a \mathrm{ds} \\
& 1 / 2\left(v^{2}-v_{0}^{2}\right)=\mathrm{a}\left(\mathrm{s}-s_{0}\right) \\
& v^{2}=v_{0}^{2}+2 \mathrm{a}\left(\mathrm{s}-s_{0}\right)
\end{aligned}
$$

\section{Problems :}

1. You are driving along the street at the speed limit $(35 \mathrm{mph})$ and 50 meters before reaching a traffic light you notice it becoming yellow. You accelerate to make the traffic light within the 3 seconds it takes for it to turn red. What is your speed as you cross the intersection? Assume that the acceleration is constant and that there is no air resistance.

\section{Solution:}

This is the motion with constant acceleration. If the acceleration of the car is a then we can write the expression for traveled distance:

$$
s=v_{0} t+\frac{a t^{2}}{2}
$$

We know the initial velocity $v_{0}=35 \mathrm{mph}=0.447 * 35 \mathrm{~m} / \mathrm{s}=15.645 \mathrm{~m} / \mathrm{s}$ we also know that after 3 seconds the car travels distance 50 meters. Then we can find acceleration

$a=\frac{2\left(s-v_{0} t\right)}{t^{2}}=\frac{2(50-15.645 * 3)}{9}=0.6811 \mathrm{~m} / \mathrm{s}^{2}$ Now we know acceleration, then we can find the final velocity: 
$v_{f}=v_{0}+a t=15.6+0.68 * 3=17.64 \mathrm{~m} / \mathrm{s}=17.64 / 0.447 \mathrm{mph}=40 \mathrm{mph}$

2. A speedboat increases its speed uniformly from 20 $\mathrm{m} / \mathrm{s}$ to $30 \mathrm{~m} / \mathrm{s}$ in a distance of $200 \mathrm{~m}$. Find

(a) the magnitude of its acceleration and

(b) the time it takes the boat to travel the $200-\mathrm{m}$ distance.

Solution:

(a) This is the motion with constant acceleration. We can use the following equation to find the magnitude of acceleration

$$
v_{f}^{2}-v_{i}^{2}=2 a s
$$

where $v_{f}=30 \mathrm{~m} / \mathrm{s}, v_{i}=20 \mathrm{~m} / \mathrm{s}, \mathrm{s}=200 \mathrm{~m}$. Then

$$
a=\frac{v_{f}^{2}-v_{i}^{2}}{2 s}=\frac{30^{2}-20^{2}}{2 * 200}=1.25 \mathrm{~m} / \mathrm{s}^{2}
$$

(b) We can find the time of the travel from the following equation:

$$
t=\frac{v_{f}-v_{i}}{a}=\frac{30-20}{1.25}=8 \mathrm{~s}
$$

3. The acceleration of an object as a function of time is $a(t)=-8 t\left(\mathrm{~m} / \mathrm{s}^{2}\right)$. Determine the

(a) velocity and

(b) the position of the object as a function of time if it is located at $x=2 \mathrm{~m}$ and has a velocity of $3 \mathrm{~m} / \mathrm{s}$ at time $\mathrm{t}=0 \mathrm{~s}$.

\section{Solution:}

(a) By definition the velocity of the object is the integral of acceleration with respect to time:

$$
v(t)=v_{0}+\int_{0}^{t} a(t) d t=3+\int_{0}^{t}(-8 t) d t=3-4 t^{2}
$$

where $v_{0}=3 \mathrm{~m} / \mathrm{s}$ is the initial velocity (at $\mathrm{t}=0$ ).

(b) The position can found as an integral of velocity with respect to time:

$$
x(t)=x_{0}+\int_{0}^{t} v(t) d t=2+\int_{0}^{t}\left(3-4 t^{2}\right) d t=2+3 t-(4 / 3) t^{3}
$$

where $x_{0}=2 m$ is the initial position (at $\mathrm{t}=0$ ) of the object.

4. A toy rocket is launched with an initial velocity of $12.0 \mathrm{~m} / \mathrm{s}$ in the horizontal direction from the roof of a $37.0 \mathrm{~m}$-tall building. The rocket's engine produces a horizontal acceleration of $2.2 \mathrm{~m} / \mathrm{s}^{2}$, in the same direction as the initial velocity, but in the vertical direction the acceleration is $g=9.8 \mathrm{~m} / \mathrm{s}^{2}$, downward. Air resistance can be neglected. How long is the rocket in the air before it hits the ground?

\section{Solution:}

The main difference of the motion of toy rocket in the problem from regular projectile motion is that in the projectile motion the motion in a horizontal direction is the motion with constant velocity (acceleration is 0 ), but in our case the motion in horizontal direction is the motion with constant acceleration.

Now we can write down the main equations, which describe the motion, and identify the known and unknown variables in these equations. There are two sets of equations:

Set 1: motion along $\mathrm{x}$ axis - motion with constant acceleration. There are two independent equations which describe this motion

$$
x(t)=x_{0}+v_{0} t+2.2 \frac{t^{2}}{2}=12 t+1.1 t^{2}
$$

Here $x_{0}=0$ (initial position), $v_{0}=12 \mathrm{~m} / \mathrm{s}$ - initial horizontal velocity.

$$
v_{x}(t)=v_{0}+2.2 t=12+2.2 t
$$

Set 2: motion along vertical $y$-axis. This is the free fall motion. There are three equations, which describe this motion. Only two equations are independent, but we can keep all of them 


$$
\begin{gathered}
y(t)=y_{0}-9.8 \frac{t^{2}}{2}=37-4.9 t^{2} \\
v_{y}(t)=-9.8 t \\
v_{y}^{2}(t)=-2 \times 9.8 \times[y(t)-37]
\end{gathered}
$$

Here $y_{0}=37 m$ - initial y-coordinate of the rocket and initial vertical (y-component) component of the velocity is zero.

At the final point the rocket hits the ground. It means that the final $y$-coordinate of the rocket is 0 . We can substitute this value in equation (3) and find the travelled time

$$
0=37-4.9 t^{2}, t=2.7 s
$$

\section{III.CONCLUSION}

The branch of mathematics in which the notion of an integral, its properties and methods of calculation are studied. Integral calculus is intimately related to differential calculus, and together with it constitutes the foundation of mathematical analysis. The origin of integral calculus goes back to the early period of development of mathematics and it is related to the method of exhaustion developed by the mathematicians of Ancient Greece. This method arose in the solution of problems on calculating areas of plane figures and surfaces, volumes of solid bodies, and in the solution of certain problems in statistics and hydrodynamics. It is based on the approximation of the objects under consideration by stepped figures or bodies, composed of simplest planar figures or special bodies (rectangles, parallelopipeds, cylinders, etc.).

\section{REFERENCES}

[1]. Edmund Taylor Whittaker (1904). A Treatise on the Analytical Dynamics of Particles and Rigid Bodies. Cambridge University Press. Chapter 1. ISBN 0-521-35883-3.
[2]. Joseph Stiles Beggs (1983). Kinematics. Taylor \& Francis. p. 1. ISBN 0-89116-355-7.

[3]. Thomas Wallace Wright (1896). Elements of Mechanics Including Kinematics, Kinetics and Statics. E and FN Spon. Chapter 1.

[4]. Russell C. Hibbeler (2009). "Kinematics and kinetics of a particle". Engineering Mechanics: Dynamics (12th ed.). Prentice Hall. p. 298. ISBN 0-13-607791-9.

\section{Cite this article as :}

S. Sathyapriya, P. Jeevanantham, M. Mukesh, R. Lokesh, T. Selva Muhillan, "Application of Integral Calculus in Kinematics", International Journal of Scientific Research in Science and Technology (IJSRST), Online ISSN : 2395-602X, Print ISSN : 23956011, Volume 6 Issue 5, pp. 91-94, September-October 2019. Available at doi : https://doi.org/10.32628/IJSRST19656 Journal URL : http://ijsrst.com/IJSRST19656 